\title{
Creating a Flexible Preservation Infrastructure for Electronic Records
}

\section{Karen Estlund and Heather Briston \\ University of Oregon}

kestlund@uoregon.edu, hbriston@uoregon.edu

\begin{abstract}
As universities begin to address their first significant collections of electronic records, the needs of the collections often outstrip the resources and support available. This poster illustrates the steps taken to transition and preserve a presidential electronic records collection into an university archives with limited systems support and preparation for future preservation needs. The infrastructure created was designed to quickly ingest at-risk records and allow for file migration and system evolution as future technologies are implemented.
\end{abstract}

\section{Case}

- University of Oregon (UO) President retired after 15 years

- First president to create significant amounts of electronic records

- Records of the presidency are the most important collected by the University Archives and Libraries - Oregon Administrative Rule 166-475, the Oregon University System records retention schedule, [1] the bulk of records created in the office are deemed as permanent and must be transferred to the archives when no longer active

\section{Preservation Planning}

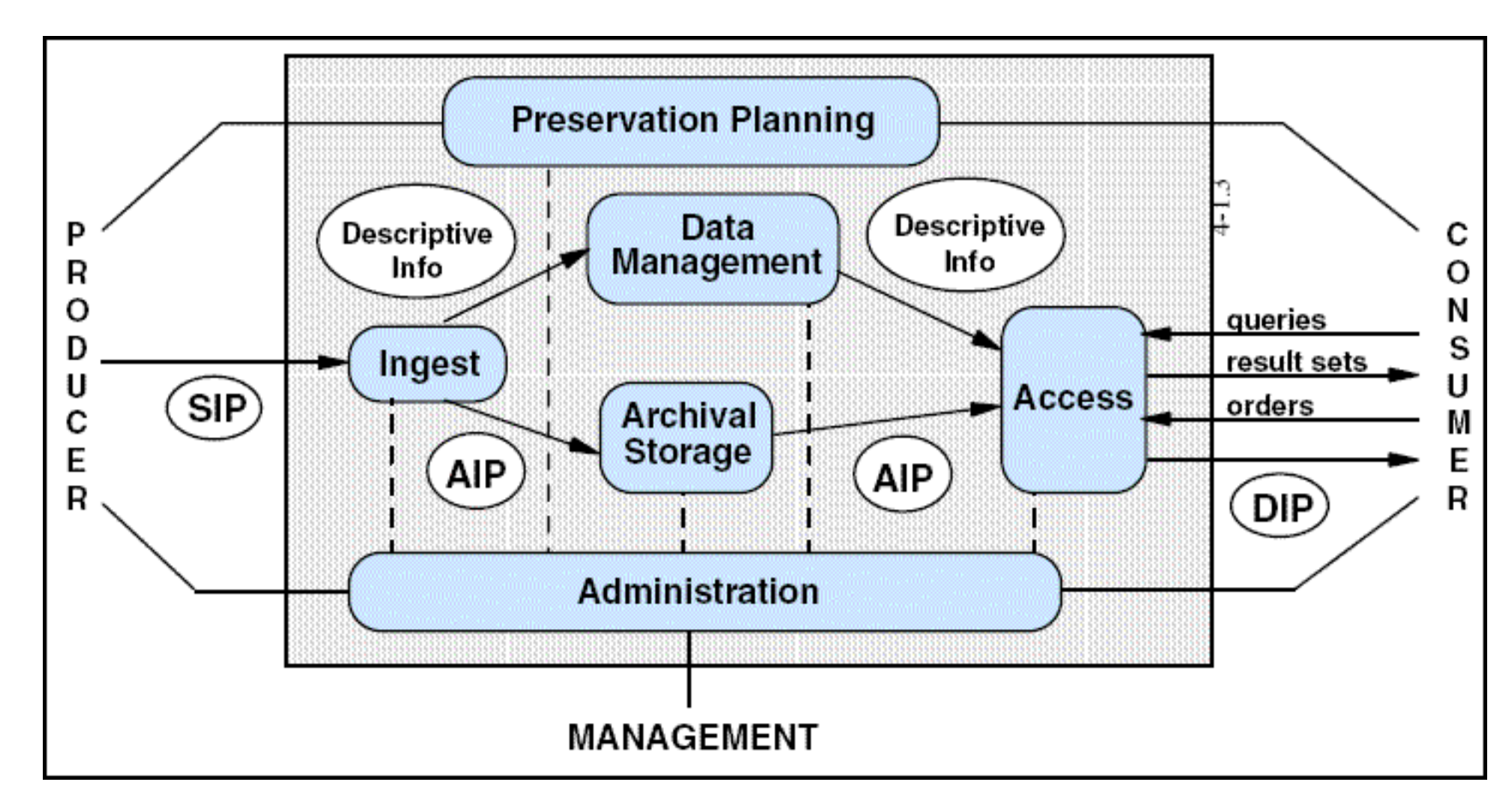

Fig. 1. OAIS Reference Model [2]

\section{PLATTER: DPE Repository Planning Checklist and Guidance [3] Highlights}

Q1.1 What is the source of the repository's mandate? Government

- Q2.2 How many distinct digital objects do you expect to archive per year? 20,000

- Q3.4 How sensitive is the most sensitive material in the repository? Highly

Technical Plan

Goal 5.1 IT infrastructure must be capable of coping with the scale of data storage, processing and transport appropriate for the repository

Ability of systems to cope with scale of repositories operation to be reviewed annually by the Digital Systems Committee Repository must have adequate network speeds, processors, and scalable storage plus back projected by 3 years into the future

Maintain a record of all changes to IT infrastructure

Succession Plan

Goal 7.1 The preservation tasks are ensured even beyond the existence of the digital repository

Objects and data will forward to the Oregon State Archives in event of dissolution of the repository

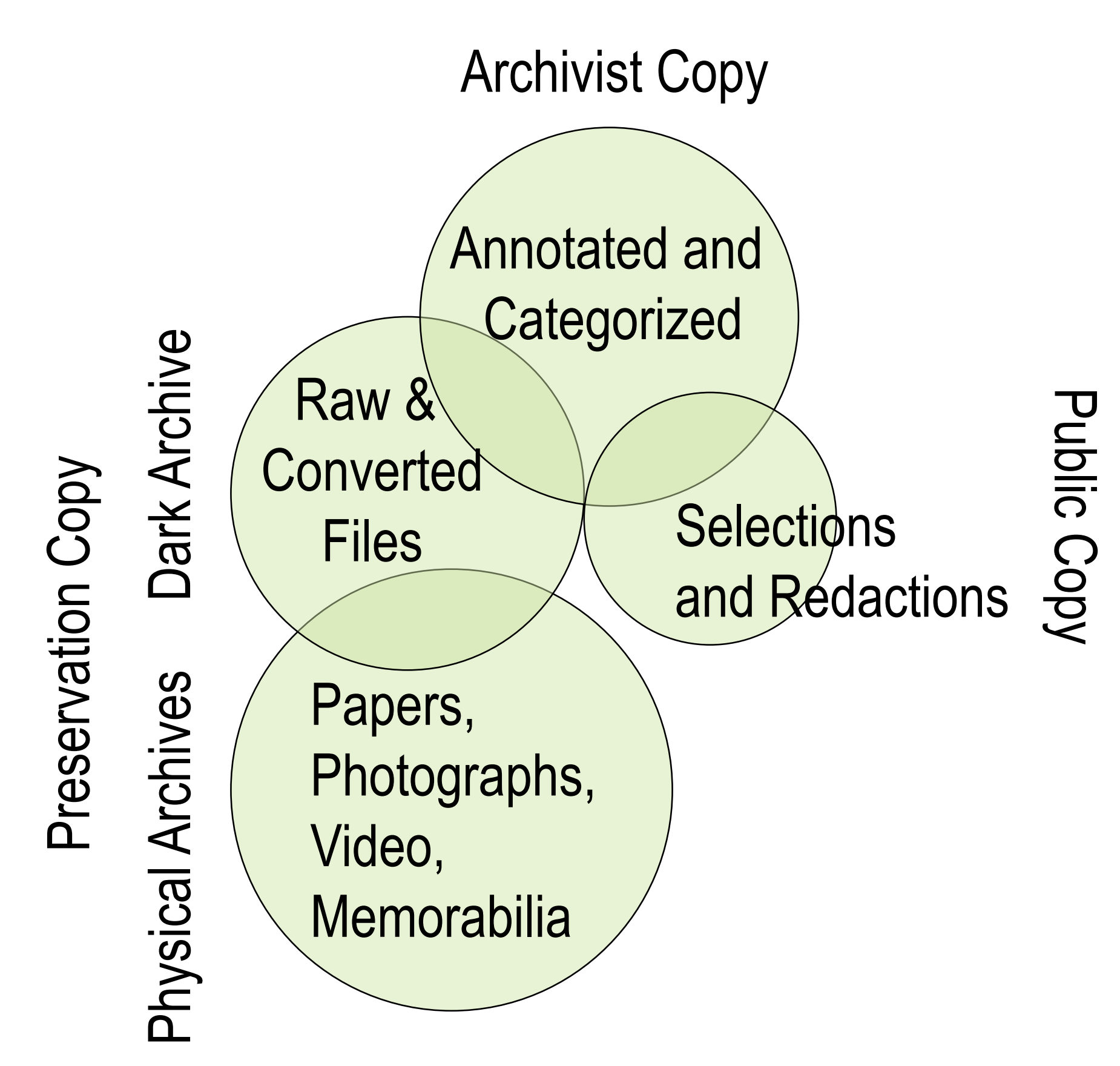

Fig. 2. Relationships of data for preservation and access of presidential records
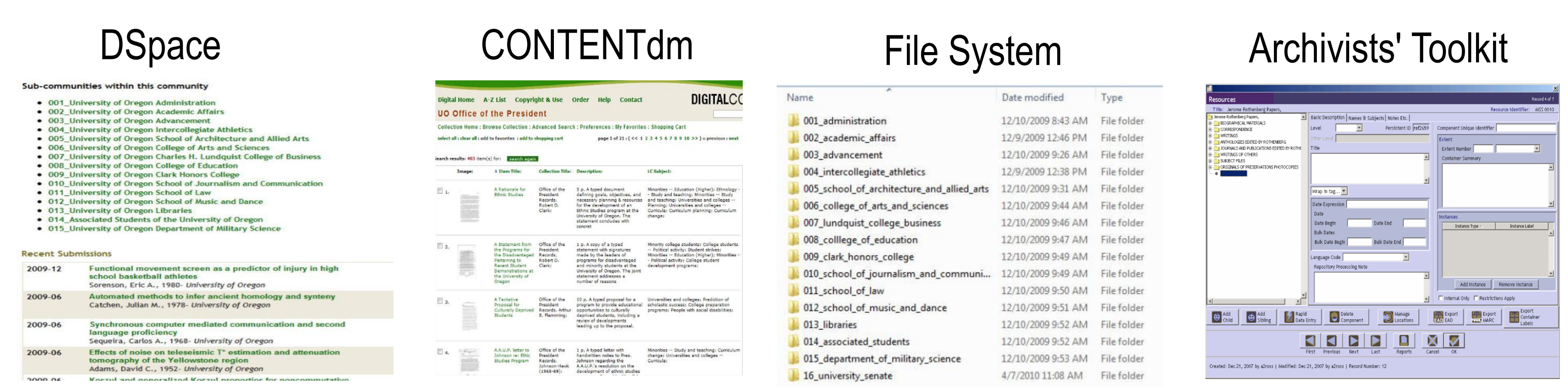

Fig. 3. Systems in place at UO Librarie

File system and Archivists' Toolkit chosen for expediency, familiarity for the archivist, security, ability to monitor file types, ability to link to multiple versions, and collection level description.

\section{Administration}

Negotiating Submission

- Trepidation regarding transfer of sensitive materials

- Extensive customer support and training: file naming, categorization, curation

Policies and Issues

- Oregon Public Records law [4]

- Exemptions from disclosure: confidentiality, privacy, copyright

Archival Formats

- Defining standard formats and refresh rates

- Establishing header/footer notation to append for context

- Inventory: DROID (http://droid.sourceforge.net)

Libraries Support

- Working with producer: University Archivist, Electronic Records Archivis

- Managing files, system, monitoring, and refreshing data and standards: Digital Collections Coordinator

- Backup and server/system administration: Library IT System Administrator

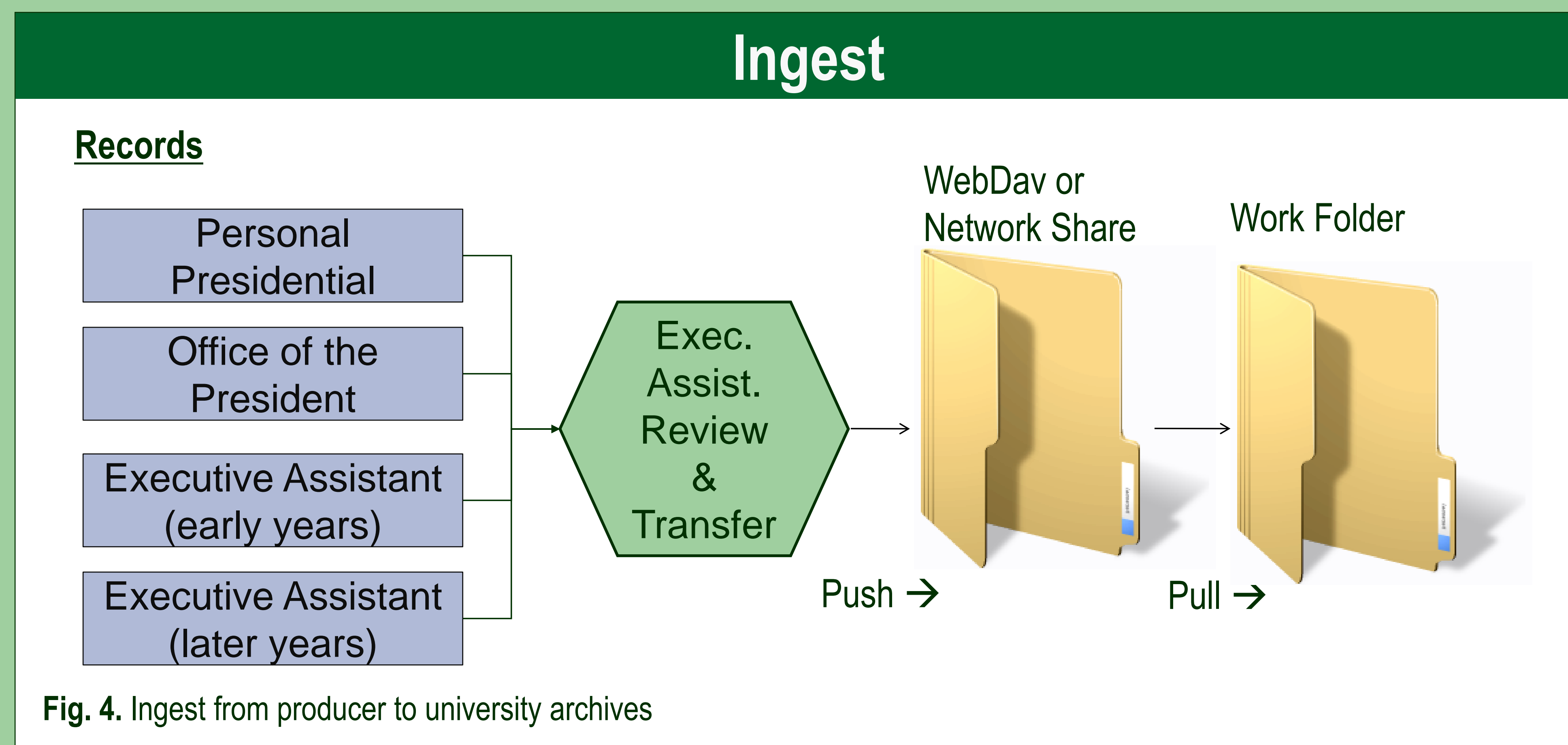

\section{Data Management and Archival Storage}

\section{Data Management}

- Metadata added using Archivists' Toolkit, exported to XML file and stored with data

- Confidential records labeled

- DROID output inventory file stored with data

Archival Storage

- Raw and preservation files with metadata moved to staging area

- Script runs to move files to dark archive and maintain hierarchy of records

- Checksums run on dark archive

- Backups (incremental run nightly, full every 2 weeks, 2 copies on LTO-4 tapes)

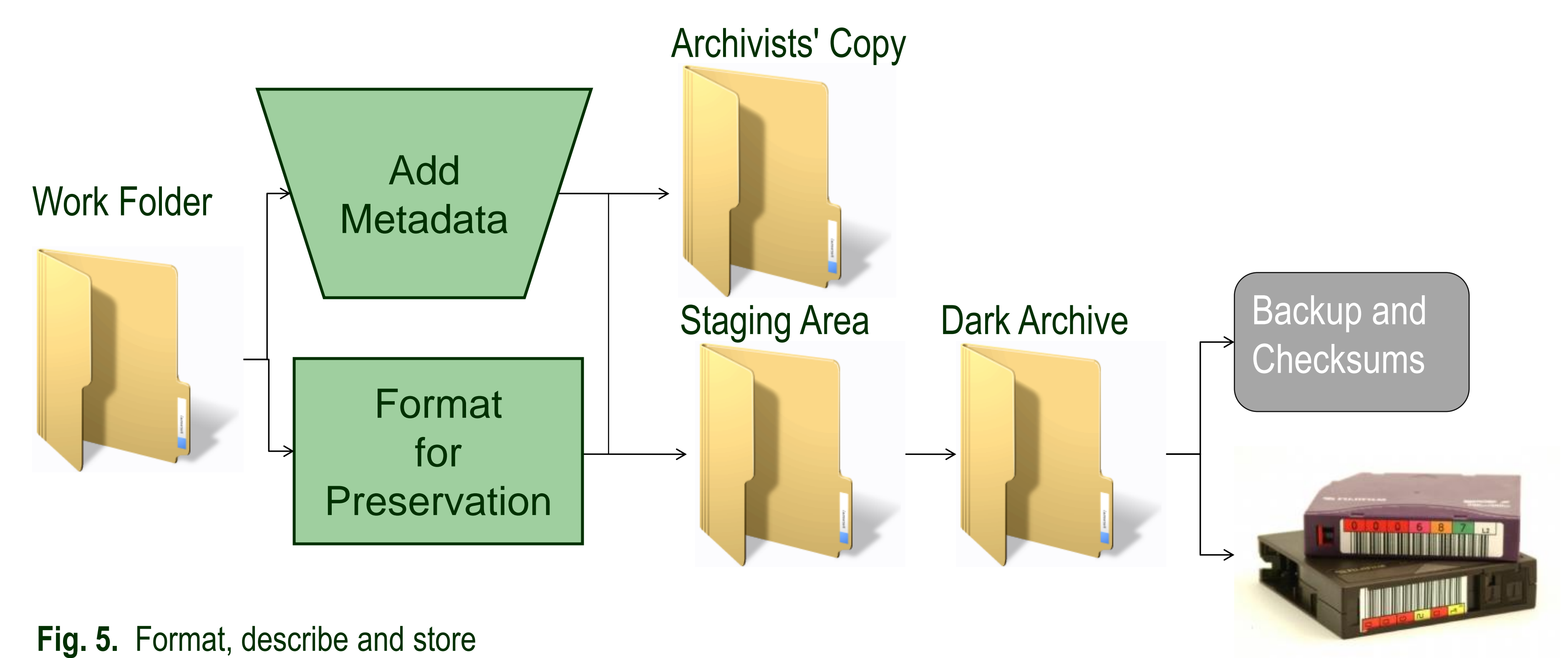

Fig. 5. Format, describe and store

\section{Dissemination and Access}

A collection level Finding Aid is export from Archivists' Toolkit and added to the Northwest Digital Archives (http://nwda.wsulibs.wsu.edul)

Selected Records are added to a terminal for viewing in University Archives and the presidential collection online (http://oregondigital.org/digcol/uopres) and the UO institutional repository, Scholars' Bank (http://scholarsbank.uoregon.edu)

Reference or FOIA (Freedom of Information Act Requests) are mediated by the University Archivist and Public Records Officer

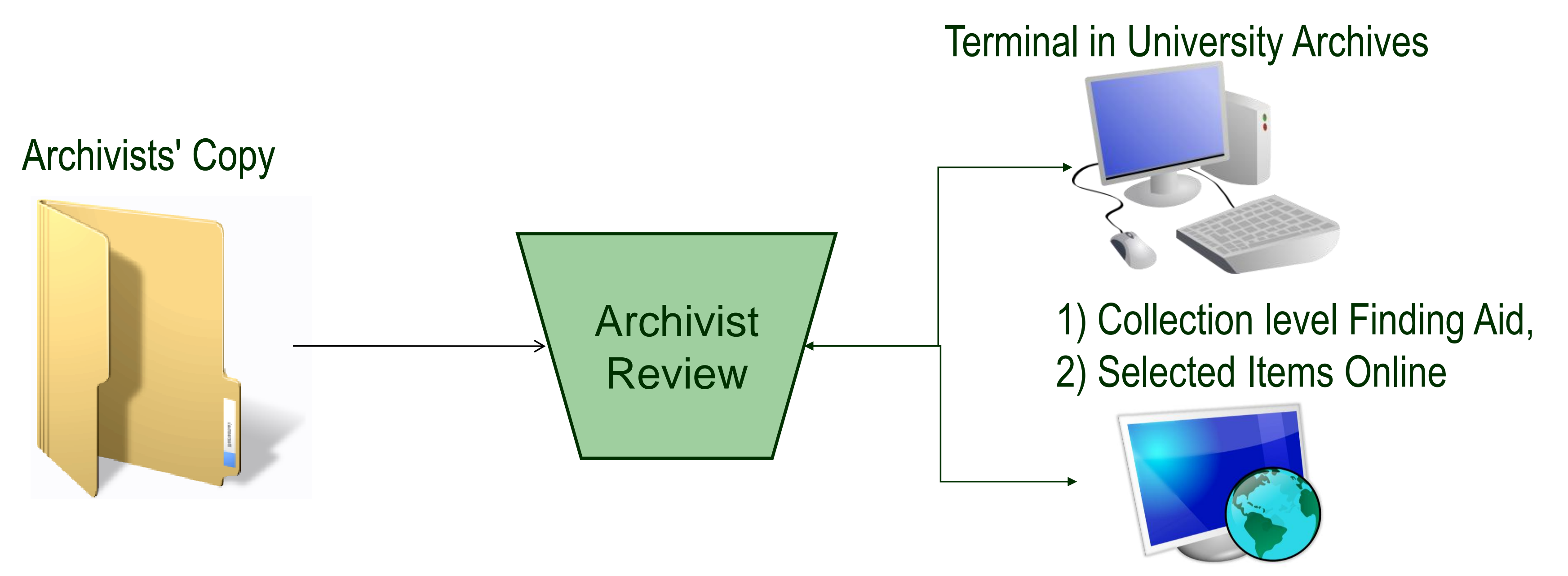

Fig. 6. Methods of Access

\section{Conclusion}

Although it was unrealistic to implement a fully OAIS compliant repository in time to collect these important records, by following the tools and standards provided by the OAIS model and the PLATTER toolkit, we were able to implement a transitional system based on the file system with existing tools that meets current needs and can easily be adapted as future technologies are integrated.

\section{References}

1. Oregon Administrative Rule, Secretary of State, Archives Division, Oregon University System Records, http://arcweb.sos.state.or.us/rules/OARS 100/OAR 166/166 475.html

2. Reference Model for an Open Archival Information System (OAIS) CCSDS 650.0-B-1 Blue Book (January 2002), http://public.ccsds.org/publications/archive/650x0b1.pdf

3. DigitalPreservationEurope, (April 2008), "DPE Repository Planning Checklist and Guidance DPED3.2", http://www.digitalpreservationeurope.eu/publications/reports/Repository Planning Checklist and Guidance.pdf 4. Oregon Revised Statutes, Chapter 192, Records, Public Reports and Meetings (Public Records Law), http://www.leg.state.or.us/ors/192.htm 